\title{
Linking research, education and citizen codesign: compact cities as social intensification
}

\author{
Jenny Stenberg ${ }^{1} \cdot$ Liane Thuvander $^{2}(1) \cdot$ Jaan-Henrik Kain ${ }^{1}(1) \cdot$ Marco Adelfio $^{3}(\mathbb{0}$
}

Received: 23 December 2020 / Accepted: 6 September 2021 / Published online: 6 October 2021

(c) The Author(s) 2021

\begin{abstract}
Both research and policy argue for more compact cities, but there is little clarity regarding which urban qualities must be made more compact to achieve the purported benefits. This paper discusses an example of how to conduct immersive and localised studies by connecting research and education to community outreach. Three potential positive outcomes of linking are examined: (a) linking may improve research activities, (b) linking may have a positive impact on student learning, and (c) better valorisation of research results may be achieved. Within a master's course, architectural students used codesign methods to investigate how the compact city concept can be understood and applied at the neighbourhood level; this assignment was formulated within a research project. The researchers performed observations and feedback tutorials, and the students applied mixed methods, including a literature review, meetings with researchers and stakeholders, site analysis, interviews and a pop-up workshop with residents, strategy development, design proposals, and feedback meetings with critics and local stakeholders. The results show that this linking may contribute significantly to research activities, as the results of a collaborative process between students and local residents were noteworthy. Rather than focusing on the physical environment, the residents argued that the starting point for urban development should be the social aspects. The residents helped the students understand what social aspects to focus on and how to think about certain locations. In terms of education, the collaboration gave students access to the latest research. Better valorisation of research results was achieved with actors at the local level. However, higher up in the municipal hierarchy, valorisation remained a challenge. Linking research and education to community outreach is not particularly common, even if linking all three activities has the potential to lead to systemic change.
\end{abstract}

Keywords Linking research, education and community outreach $\cdot$ Higher education · Compact city $\cdot$ Codesign $\cdot$ Citizens $\cdot$ Inhabitants $\cdot$ Residents $\cdot$ Social intensification

Liane Thuvander

liane.thuvander@chalmers.se

Extended author information available on the last page of the article 


\section{Introduction}

Education outreach has existed for decades at certain universities and, where applied, has often evolved from temporary projects into integrated and institutionalised complex models of education intertwined with society (Hirt and Luescher 2007; Sandmann et al. 2016). This has sometimes generated permanent centres for university-community partnerships (Rogge and Rocha 2014). Such systematic linking of education to community outreach may drive action for social change (Howard 2010) and can be considered a way for universities to give something back to the local community, which is necessary to support long-term interaction with civil society (Stenberg and Fryk 2012). Bringing authorities and city planners into community outreach education is a fruitful way to help them see residents as credible participants (Derr 2015).

Research that is closely linked to society has a long history. It has traditionally been labelled action research (Argyris et al. 1985; Reason and Bradbury 2001) or participatory action research (Kindon et al. 2007). Today, action research is often referred to as transdisciplinary research (Hirsch Hadorn and Hoffmann-Riem 2008) and has the potential to build common understanding and foster learning (OterosRozas et al. 2015). Participatory action research processes can be empowering, not only in the local setting, but potentially also in relation to wider planning and policy systems (Kindon et al. 2007). A particular type of community outreach in the design professions involves visualisation tools for communication. Previous research has examined whether using such tools can reduce the communication gap between design professionals and residents (Al-Kodmany 2001) and how visualisations can be designed to better reveal issues of public concern (Schoffelen et al. 2015).

Linking both research and education to community outreach is still underexplored, even though doing so has the potential to lead to systemic change (McNall et al. 2015). Establishing transdisciplinary knowledge alliances is critical for supporting the engagement of practitioners, students, and researchers in joint inquiry and learning based on curiosity, self-reflexivity, respect for the diversity of group members, and democratic dialogue. Overall, the goal is to find ways to address complex societal phenomena or challenges using socially robust knowledge (Novy 2012). Joint knowledge production can affect the public procurement of building projects by supplementing such projects with requirements to address certain social issues, such as the employment of local unemployed youth (Stenberg and Fryk 2012). Such three-dimensional links can also contribute to the development of the institutions involved (e.g., universities, municipalities) through organisational learning (Argyris et al. 1985), preparing them to better meet contemporary and future societal challenges linked to accelerating urbanisation processes (Trencher et al. 2016).

The present paper explores the linking of research, education, and community outreach; more specifically, it asks how students can initiate and drive collaborative knowledge production processes to develop knowledge about locally relevant urban qualities. The study is part of a larger research project on compact cities. It is related to the municipality's effort to densify suburban neighbourhoods in the city of 
Gothenburg, e.g., to tackle contemporary challenges such as providing housing for a growing population, offering locally accessible services and amenities, promoting economic development and employment, and addressing spatial segregation (City of Gothenburg 2014).

An additional contextual factor is that Gothenburg is a city marked by strong socioeconomic segregation, where certain housing areas are highly stigmatised and excluded from the rest of the city (Andersson et al. 2009). As a result, those housing areas suffer from a lack of access to public authorities and functions, and there is a mutual lack of trust between inhabitants and public officials (Andersson 2002). Although dialogue with stakeholders, including inhabitants, is part of most education programmes for architects, insights into how to engage and interact with strongly disenfranchised communities is often lacking, which perpetuates similar patterns within the architectural practice (Stenberg and Fryk; Listerborn 2007).

The aim of the paper is therefore to study whether and how linking education, research, and community outreach can lead to improved learning regarding engagement with weak societal groups. It draws on the contributions made by graduate students of the international master's programme 'Architecture and Planning Beyond Sustainability' at Chalmers University of Technology, Gothenburg, Sweden. In the course 'Design and Planning for Social Inclusion', engagement with excluded and stigmatised citizens is a core topic. The students have interpreted and applied the compact city concept through reality-based studies at a very local level, leading to a reinterpretation of the city's densification goals through a context-related and socially rooted view of densification, thus emphasising additional layers of the topic of compact cities.

The paper identifies three potential positive outcomes of this linking of education, research, and community outreach:

(a) The research activities themselves may improve,

(b) There may be a positive impact on student learning, and

(c) Better valorisation of research may be achieved.

\section{Methods}

The present study examines how students can initiate and drive collaborative knowledge processes, focusing on architectural students using codesign methods (Steyaert and Hervé 2005; Faga 2006). Through such methods, designers enter into a joint creative process with members of the public who are interested in improving their neighbourhoods (Sanches and Frankel 2010). However, codesign also implies that the power to take decisions has to be shared with residents (Sanders et al. 2008), as the design of urban environments affects the activities of a community and should therefore be based on its needs and values (Sanches and Frankel 2010). Codesign methods were used to investigate how the compact city concept can be understood and applied at the neighbourhood level. Here, such methods are particularly relevant because there is little clarity in the research and policy on what actually needs to 
be made more compact to achieve the purported benefits the compact city delivers (Echenique et al. 2012; Neuman 2005). The work was performed at the intersection of research, education, and community outreach, and it involved students, teachers, researchers, civil society, and a housing company.

The approach the researchers took to analyse the students' processes and results was action oriented (Reason and Bradbury 2001), involving methods such as participant observations of meetings and activities (Dewalt and Dewalt 2010), for example, in meetings with the local community; the critiques of the students' final assignment with participants from the municipality and architects; analyses of text and drawings (Groat and Wang 2002); regular feedback meetings with the students in tutorials; and a focus group meeting with the researchers after the course ended. The students applied mixed methods, including a literature review, meetings with researchers and stakeholders, site analysis, dialogues with residents, strategy development, and development of design proposals. The students themselves designed the dialogue methods they employed based on the course content and literature (e.g., Steyaert and Hervé 2005; Ranger and Westerberg 2004) and included, for example, short interviews on the street; pop-up workshops with residents; feedback meetings with local stakeholders, municipal representatives, and architects; and an exhibition of the work in the community centre. The dialogue methods are described in more detail in "Master's students' project work" section.

The compact city concept was explored by a group of five students in an international 12-week-long, full-time master's course entitled 'Design and Planning for Social Inclusion' in 2015 (Roussou et al. 2019). The students' ages ranged from 23 to 26. The academic background of the students was not uniform; three had a bachelor's in spatial planning, whilst the other two had a bachelor's in architecture. In Sweden, several academic programmes may lead to a potential career in urban planning, such as architecture, spatial planning, and geography. Since the master's course was given by the Department of Architecture at Chalmers University, the focus was on planning as an applied activity aimed at direct urban change and on the design outcomes of this activity.

The aim of the course was to learn how to deal with renovation and urban development in situations marked by segregation and social exclusion by applying participatory methods involving residents. The course was conducted and located in Hammarkullen, a stigmatised, large-scale housing area in the outskirts of Gothenburg. The premises for the students were located in the Centre for Urban Studies, a collaborative higher education centre, in a building close to the main square of Hammarkullen. The local context provided a unique possibility for the students to become highly familiar with the area under study. For example, the local public housing company that owns all rented apartments in the area has collaborated closely with the master's course for a long time, building trustful and mutually beneficial relationship over the years. The same applies to contacts with the local city administration, particularly their youth activities. The students' projects were exhibited in the local community centre for feedback and long-term outreach purposes.

A typical student project in this course is completed in small groups and carefully selected to connect to ongoing, real projects and give the students possibilities to develop skills for their future work in an integrated way and with a local 
participatory impact. The project types are design proposals, design and build projects, game or tool development for design, or strategic planning (Roussou et al. 2019). In this study, the students developed both a strategic plan and design proposals. Material from the course can be found at suburbsdesign.wordpress.com.

The students' specific assignment was to engage in codesign with residents to explore and understand the meaning of densification in a suburb from the 1960s and 1970s. What compact city qualities are relevant and desirable in such areas? The assignment was formulated within a research project called Compact cities? Exploring qualities, drivers, and strategies for mixed-use and dense urban development. Hammarkullen is one of the case areas in this project. Other case areas of the research project are situated in Rotterdam, the Netherlands, and Barcelona, Spain. One of the authors supervised the students' project; the others were lecturers in the course or resource persons.

\section{The neighbourhood of Hammarkullen}

Coming to Hammarkullen in the end of September, I wasn't sure what was awaiting for us. Since I am from Göteborg, I have had my preconceptions about the million programme suburbs around the central city. The first impressions coming up from the tram station to the square might have been what I had expected, but it didn't take long before I started to re-write my mental image of Hammarkullen and the suburbs as a whole. The suburb isn't grey but very green. People are most of the times friendly and welcoming. This change of perception also made me, and I think most of us, a bit naïve- "This whole thing that Hammarkullen is a problem area must be a misunderstanding," sort of. When we started to do interviews, we found out that there are problems with criminality and drugs, which we have in other parts of Göteborg, as well, but here, it seemed to be more open and almost a part of the identity of the neighbourhood and the people living there. Things like, "There is nothing good with Hammarkullen," or "We are only good in drugs and shootings" were commonly said, especially by younger kids. But most people really liked living in Hammarkullen and felt safe there. (Student 2)

The study site is a satellite suburb of Gothenburg, located about $10 \mathrm{~km}$ northeast of the city (Fig. 1). It takes about 15 min from the city centre by tram (three passing lines) and about $10 \mathrm{~min}$ by car. Gothenburg is the second-largest city in Sweden and has a population of 548,000, of whom $25 \%$ were born abroad (City of Gothenburg 2016a).

The Hammarkullen area was constructed during the 1960s and 1970s to respond to urgent housing needs and housing degradation in the city centre. The area is predominantly free of cars, which the residents greatly appreciate. Buildings are sparsely placed, and the greenery is generous. The area includes large-scale housing, lower buildings, detached houses, and villas (Fig. 2).

Of the 8200 residents in Hammarkullen, $57 \%$ were born abroad (City of Gothenburg 2016b). There are 84 nationalities, and over 100 languages are spoken. It is a 


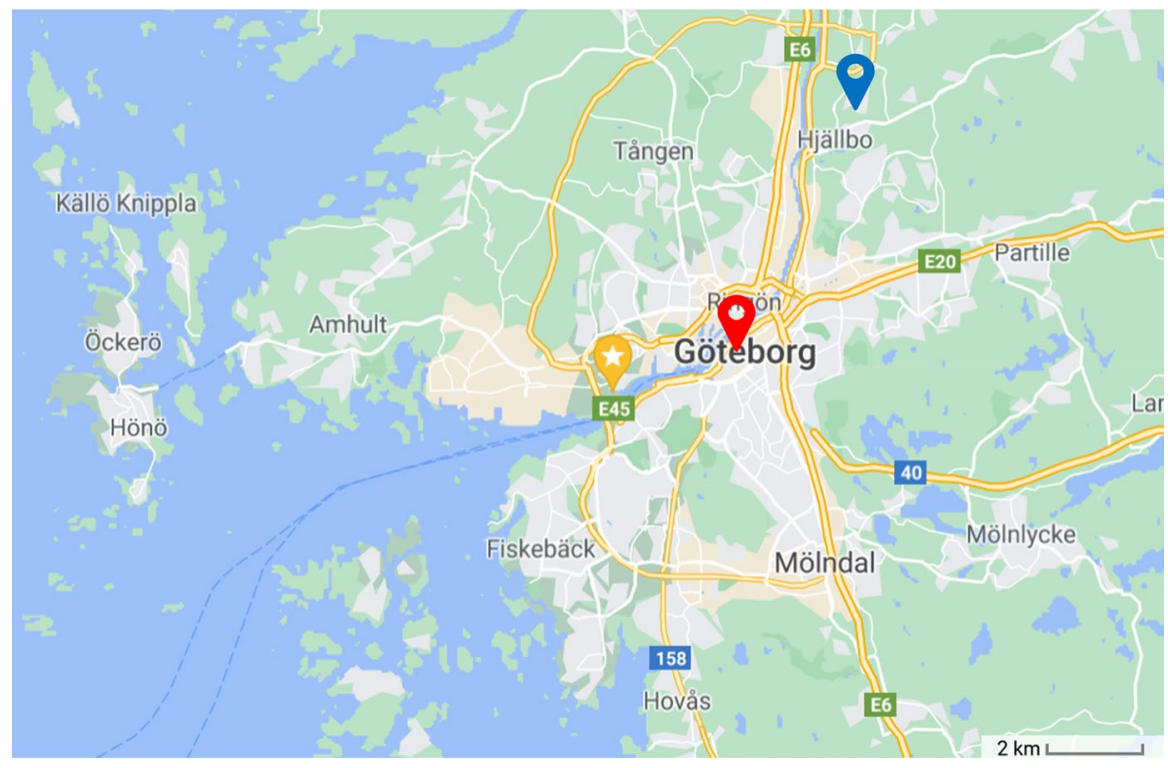

Fig. 1 Location of Hammarkullen in relation to the city centre of Gothenburg. Red=city centre, blue $=$ Hammarkullen (Map source: Google maps)

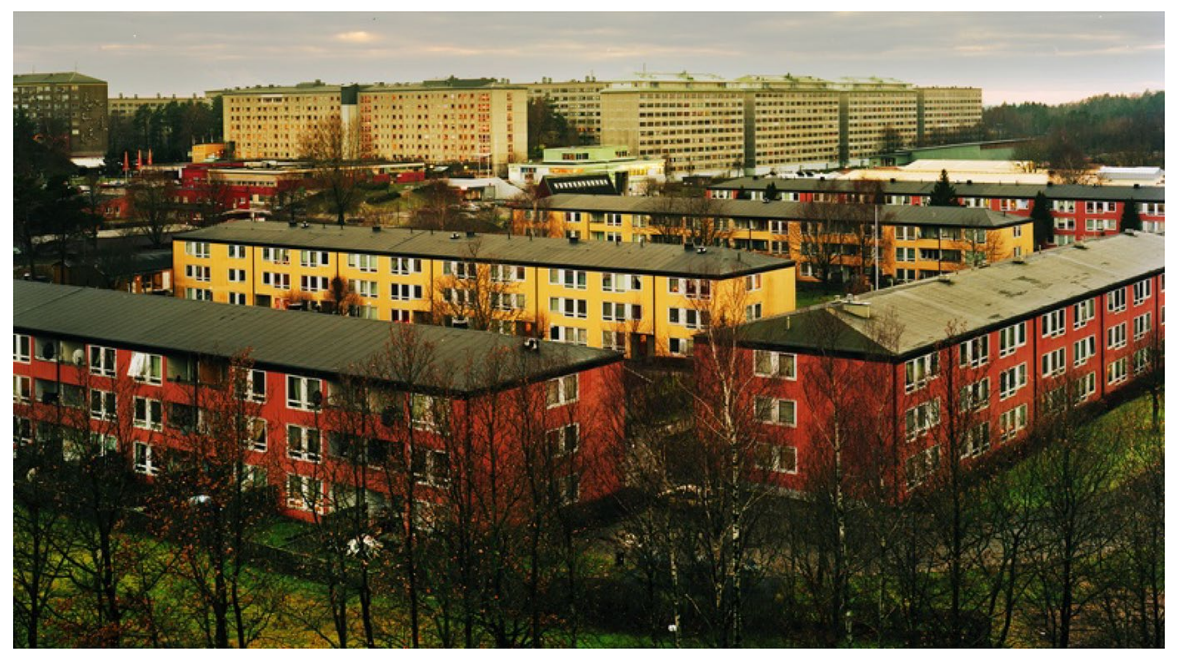

Fig. 2 Hammarkullen: large-scale housing surrounded by lower buildings. Photo: Albin Holmgren

multicultural neighbourhood, and a great deal of social life takes place in the context of associations. The area is well known for its carnival, which started in the 1970s, when many refugees came from Latin America. The carnival now attracts 40,000 spectators annually. Hammarkullen is also affected by a poor media image, which is damaging for the people living there. It has a relatively high unemployment rate 
(15.5\%) compared to the Gothenburg average (6\%). The yearly gross income differs considerably from the average in Gothenburg, with 17,100 USD (148,500 SEK) in Hammarkullen versus 31,000 USD (270,000 SEK) in Gothenburg. The area has long been stigmatised, and there has been little interest on the part of developers in investing in much-needed refurbishment and densification. With this in mind, the students set out to investigate what would happen if the idea of the compact city was applied to Hammarkullen.

\section{Master's students' project work}

Based on the question from the research project 'Compact Cities' on what compact city qualities are relevant and desirable in suburbs from the 1960s and 1970s, a literature review, and initial site observations in Hammarkullen, the students formulated the following overarching questions for their work: (1) Should the area be densified? (2) If yes, what should be made denser-the physical environment or something else entirely? (3) Where should this densification take place? For the students, the term 'densified' in the first question was not specifically related to buildings or dwellings, which allowed the adoption of a broader perspective than the one proposed in the municipality's policy documents, which merely focused on physical density. Instead, the concept of density was left open to interpretation-e.g., density of dwellings, residents, or activities - and then clarified through question 2.

In order to approach the questions, the students used mixed methods: a literature review on compact cities, meetings with researchers and stakeholders in Hammarkullen, site analysis of the area, interviews, a pop-up workshop, forming a strategy to develop Hammarkullen over time, a design proposal for two selected areas, and feedback meetings with critics and the community. The students divided their process into three phases: analysis, participation, and design. The initial literature review focused on obtaining a better understanding of the compact city concept as well as the term 'densification'; it resulted in a compilation of annotated definitions that helped the students focus, formulate questions, and contextualise their project in the ongoing discourse in the research field. The students planned their work and selected their methods by themselves under the guidance of their tutor (over a total of four meetings) and the teacher of the course. The process and interactions with different stakeholders are summarised in Fig. 3. The students' work was documented through a project logbook, exhibition posters, a physical model, and a report.

\section{Analysing the site}

The students began the analysis of the site by gathering their own impressions of the area, meeting the researchers from the compact city group, and compiling theoretical material about the compact city concept. Different types of analyses were conducted: spatial mapping (Lynch mental maps, as well as analysis of buildings, green structures, and infrastructures) and non-spatial analysis (Strengths, Weaknesses, Opportunities, Threats [SWOT]; and statistics). 
Students work process

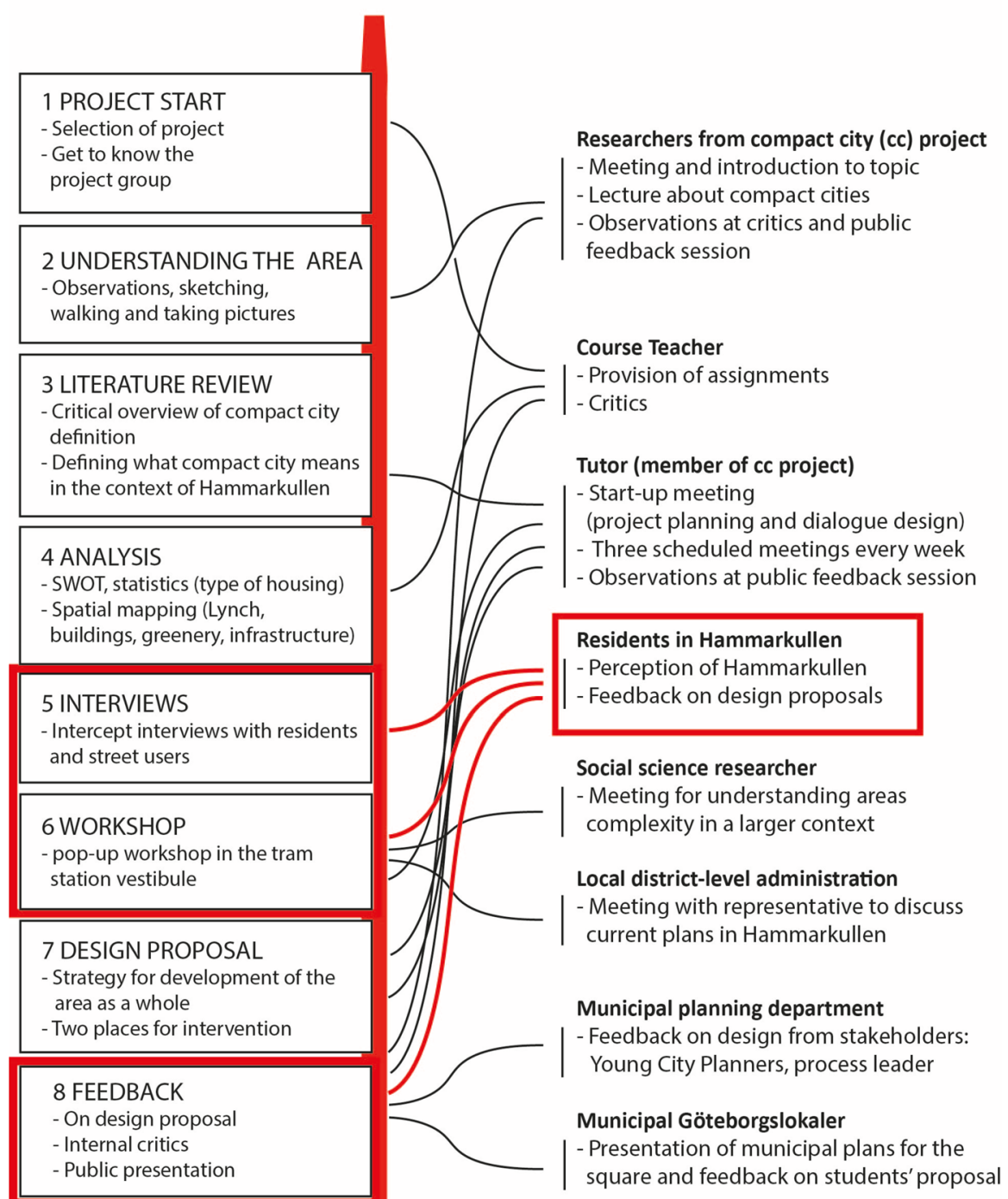

Fig. 3 Timeline-work process of the students and interactions with different stakeholders 


\section{Residents' participation}

The results from the analyses were used to prepare the next phase of the students' project, which entailed the co-creation of knowledge through participatory processes. The interviews and a pop-up workshop, all conducted by the students, are part of this process, as shown in Table 1.

Densification processes are often driven by planning offices or property owners, and plans are often developed without local people's involvement. Therefore, residents and people staying in Hammarkullen were chosen as the main group to be involved in the participatory process. Those people are local experts; they have knowledge about which places are used and how, as well as which are avoided and why. On the one hand, the students aimed to contribute to the compact city debate by exploring the issue and meaning of densification in areas such as Hammarkullen. On the other hand, they wanted to understand how development strategies and design proposals are affected when the residents and local people are involved in the process.

The participatory part started with interviews. On four different occasions (both in the morning and in the afternoon), the students conducted a total of about 48 intercept interviews, short interviews at locations where people move in everyday life. Type 1 interviews (see also Table 1) were conducted on two occasions at the most-visited places, such as the main square, its shops, and the street leading to the tram station. People were asked about the 'best things', 'movements and routes in Hammarkullen', and 'places they never visit'. Of the 34 interviewees, 23 were men and 11 women, most of them younger than 65. Type 2 interviews were conducted in the street. Passersby were asked for directions with the purpose of understanding how locals move around in Hammarkullen. The results from the interviews were used to plan the next step of the participation phase, a spontaneous pop-up workshop.

The pop-up workshop was held once in the tram stop vestibule, the most frequently visited place in the area, in order to reach a wide group of people. The tram station guaranteed a constant flow of passengers. Before the workshop, posters were hung around the area to inform people about it. A Friday afternoon was chosen with the expectation that people would be more relaxed since they had just completed the last working day of the week. During the workshop, which lasted about three hours, around 80 people participated. There was a mixture of men $(27 \%)$, women (35\%), and children (38\%). Home-baked cookies were served during the workshop. The workshop consisted of three activities: (1) describing 'If Hammarkullen were a person', (2) placing stickers on a map, and (3) creating a collage of activities and objects. The first activity gave a clear indication of the district's self-image, i.e., how residents perceive Hammarkullen. In the second activity, participants were asked to put a green (positive) and a red (negative) sticker onto a printed map of the area (Fig. 4) whilst describing the reasons for their sticker placement. The resulting map showed the main categories of desired improvements of particular places.

The participatory process, together with the initial analysis of the area, helped the students find the focus of their project and understand how to approach the compact 


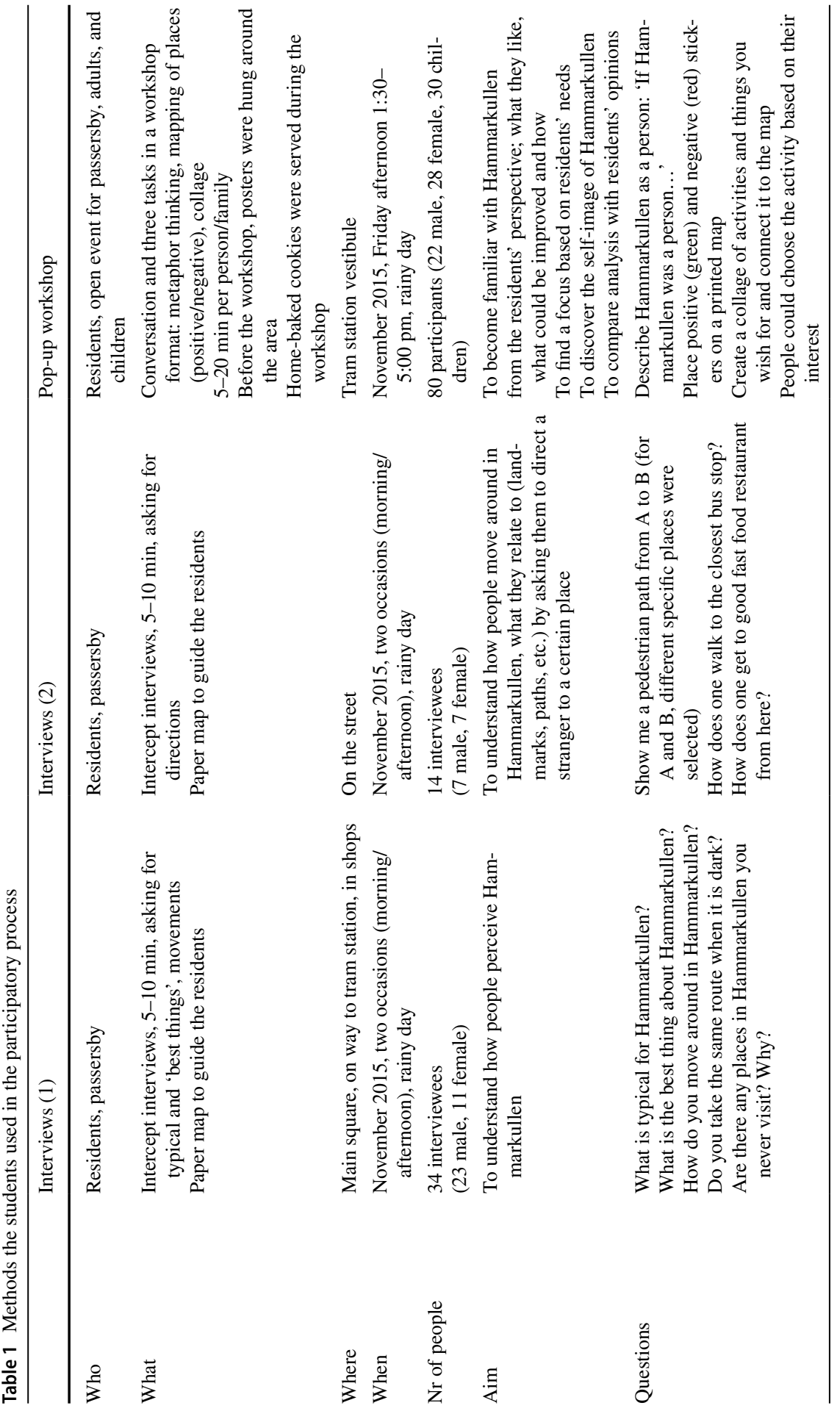




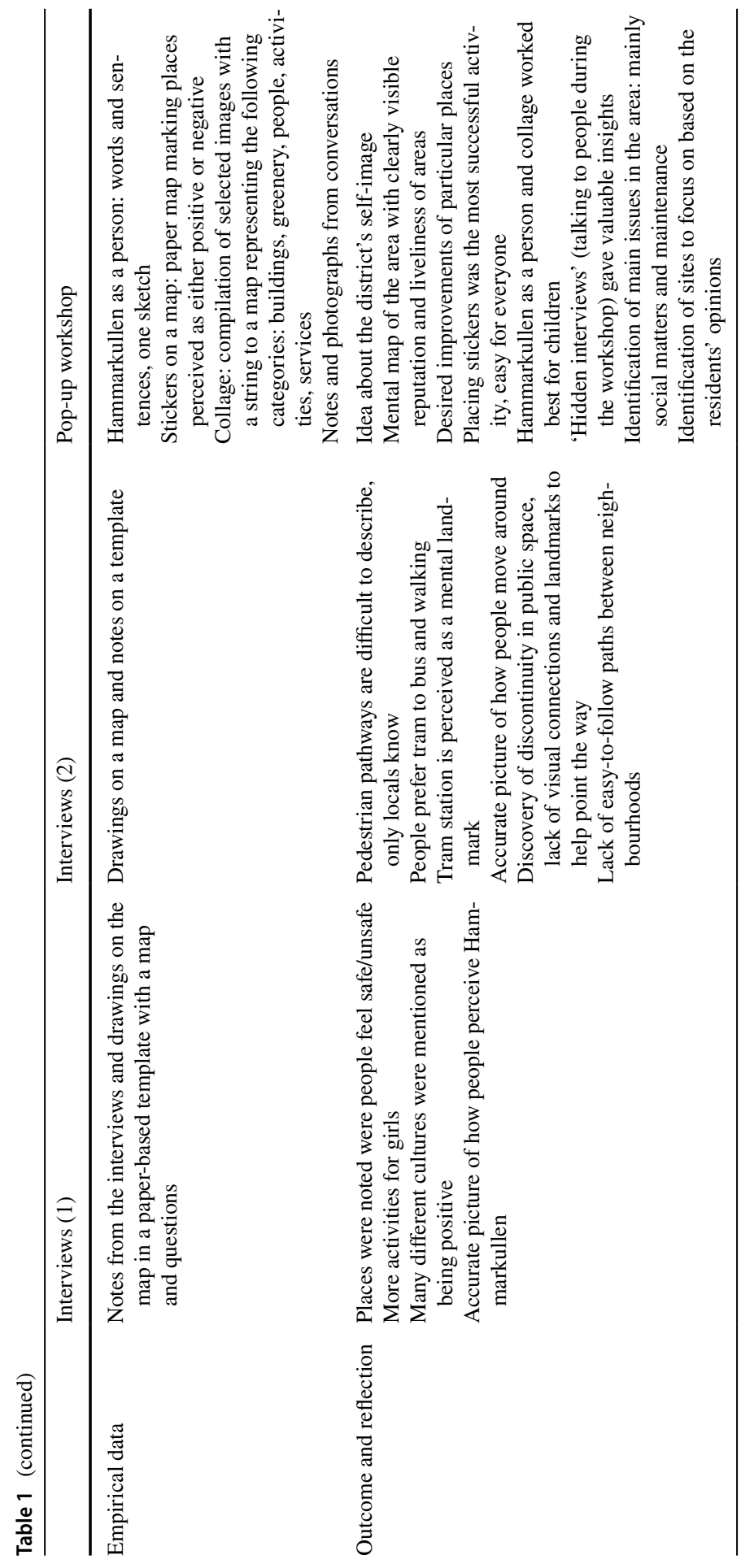




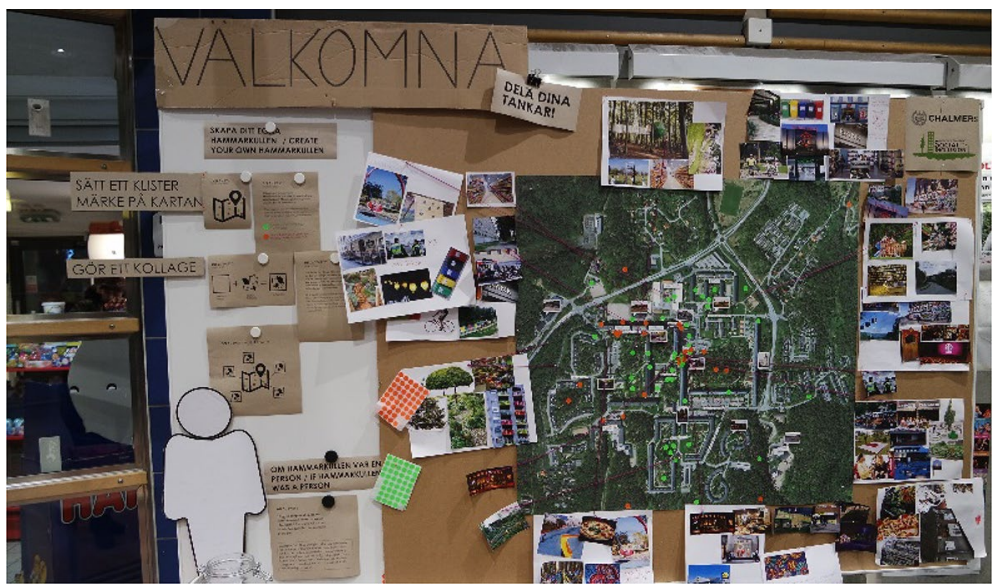

Fig. 4 People put stickers on a map and made collages (Dvorak et al. 2015). Photo: Caroline Sollerhed

city concept in Hammarkullen. The following quotations come from the residents in the students' interviews:

'We love it here, but sometimes we feel unsafe'. (mother with child; Dvorak et al. 2015, p. 60)

'I only feel safe in my apartment. I was attacked one night by the main square, and now I'm afraid to go out. For me, all these problems can't be solved by the police, maybe more activities for youngsters - university and job opportunities could improve the quality of life in this area'. (young man; Dvorak et al. 2015, p. 60)

'I live in Sandeslätt and have lived here for 31 years. I really enjoy living here, and letting my children grow up here has been very good'. (middle-aged woman; Dvorak et al. 2015, p. 61)

'More playgrounds and basketball fields in the area so that my friends would visit me'. (young man with dog; Dvorak et al. 2015, p. 61)

\section{Translating social intensification into a design strategy}

In the participatory processes, the residents focused mainly on social interaction, services and business, public spaces, and maintenance. Following these processes, the students surmised that the areas people want to improve are liveliness, identity, inclusion, safety, quality of life, and self-image. Thus, the main issues to address in Hammarkullen were identified as being linked to social matters and maintenance.

Drawing on the experience from the participatory process, the students developed a working concept: social intensification. Social intensification was set as a framework and goal for the project, and physical changes were the tools for reaching that goal. The students defined social intensification as a way to increase interaction, activities, and movement for all people, creating equal spaces, strengthening relations and links between people, and enriching their lives (Dvorak et al. 2015). 
The following is a reflection from a student on the participatory process:

We also got an idea of how people in Hammarkullen view the area and what they wish for. ... A very important fact is that people shared with us some stories, thus gave us a perspective of an insider, which we couldn't get without any participatory activities. (Dvorak et al. 2015, p. 55)

In the next step, based on the outcome of the participatory process and the initial analysis of Hammarkullen, in a joint effort, the student group developed a common vision for Hammarkullen with five indicators focusing on specific attributes of social life: identity, safety, vibrancy, maintenance, and variety. The vision is described as follows:

VISION: Compact Hammarkullen is considering its existing unique qualities whilst it's adaptable over time due to its dynamics and social life. The richness in culture, spaciousness and closeness to nature are seen as resources whilst the built environment and public space is developed to increase the quality and the intensity of life in Hammarkullen. There is a powerful network between people, buildings and open spaces trough the design qualities leading to a stronger identity. It's a kind, hospitable, safe and desirable area to live and work in for everyone. (Dvorak et al. 2015, p. $63)$.

The five social attributes mentioned above were then applied in the students' analysis of the four informational layers they identified as relevant for a densification strategy: meeting places, orientation and movements, built form, and green structure.

Concerning the layer meeting places, they found a lack of variety and therefore proposed different levels of interaction, both indoors and outdoors, with extra emphasis on places for women and girls (Fig. 5). For orientation and movement, they proposed new paths, e.g., bicycle paths, in order to create a finer network whilst keeping the central areas free of cars (Fig. 6). The layer built form included facilities on the ground floor and added balconies and other semi-private spaces. Buildings were located in empty spaces such as parking lots to save green space qualities and to activate lifeless places (Fig. 7). The green structure needs to be better maintained to encourage play and relaxation (Fig. 8).

The students saw codesign and cocreation as crucial to the successful development of Hammarkullen in a long-term perspective. To test the densification strategy, they used it to develop design proposals for two places that the residents considered to be particularly problematic and to have the greatest need for improvement.

Another useful thing was that we could choose our focus sites based on the people's opinions, pointing out Bredfällsgatan and Hammarkulletorget as the most urgent to work with. (Dvorak et al. 2015, p. 55)

The first was labelled A Safe Bredfjällssgatan (Fig. 9). The focus was placing activities in empty spaces to make the area safer and more vibrant. The place is 


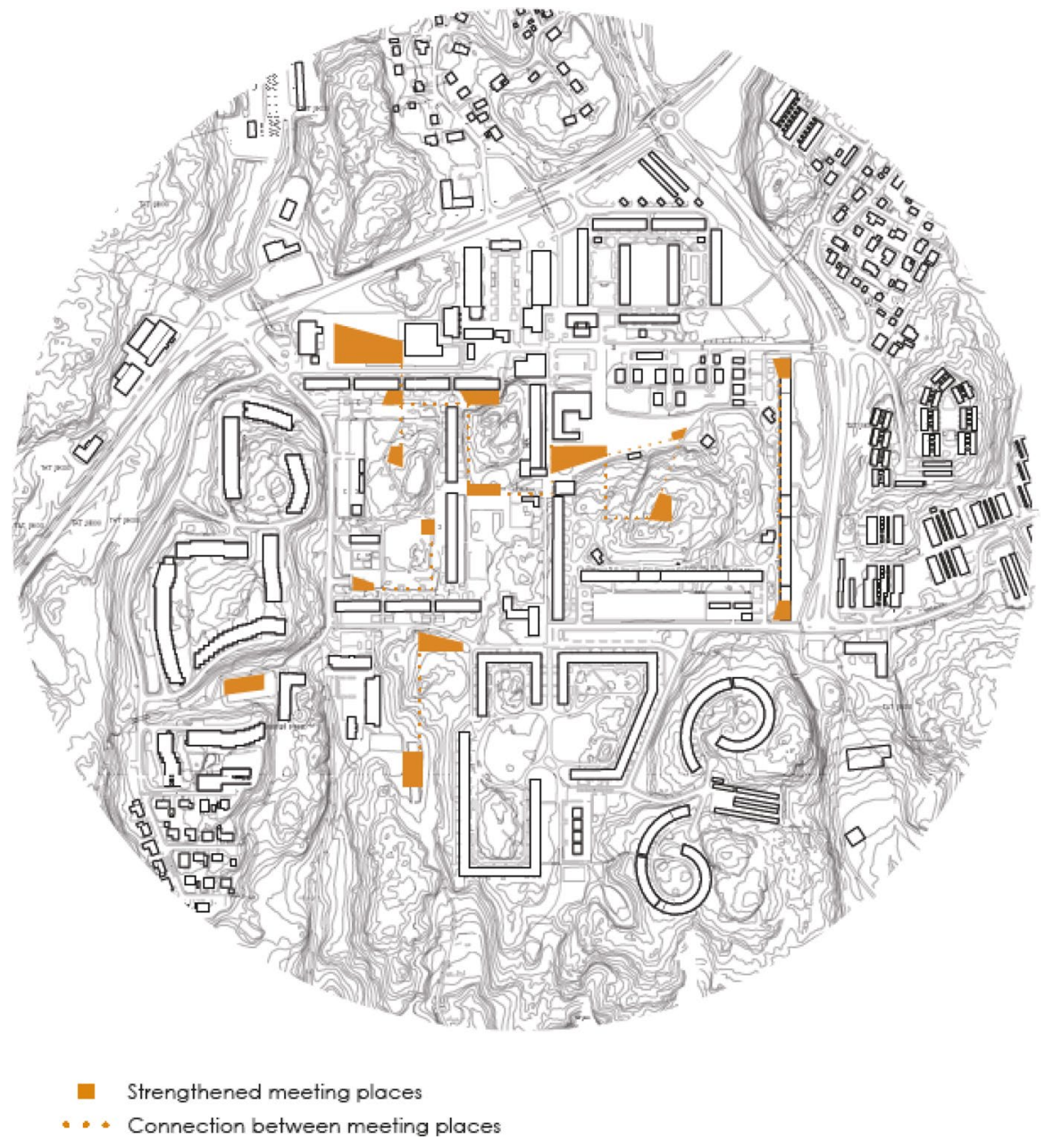

Fig. 5 Proposed changes for the meeting places layer of densification. Locations for strengthening meeting places and the creation of connections between the meeting places. (Dvorak et al. 2015)

perceived as a backside, windy, boring, grey, and untidy, but it is also the heart of the carnival that takes place one weekend every year, when it becomes vibrant, fun, and colourful. The proposal opens up the back of the building by adding 'boxes' for services, shared space, or sewing workshops where preparations for the carnival can take place. A space for dance studios was added, as well as a football field that could be transformed into an ice-skating rink. Mosaic decorations made by local youth, which were illuminated at night for better lighting, were another element of the project. The proposal makes the Hammarkullen carnival, which is important for the identity of the area, more visible.

The second design proposal was named A Vibrant Hammarkullen Square (Fig. 10). In this proposal, the square is an important node, as it contains the only 


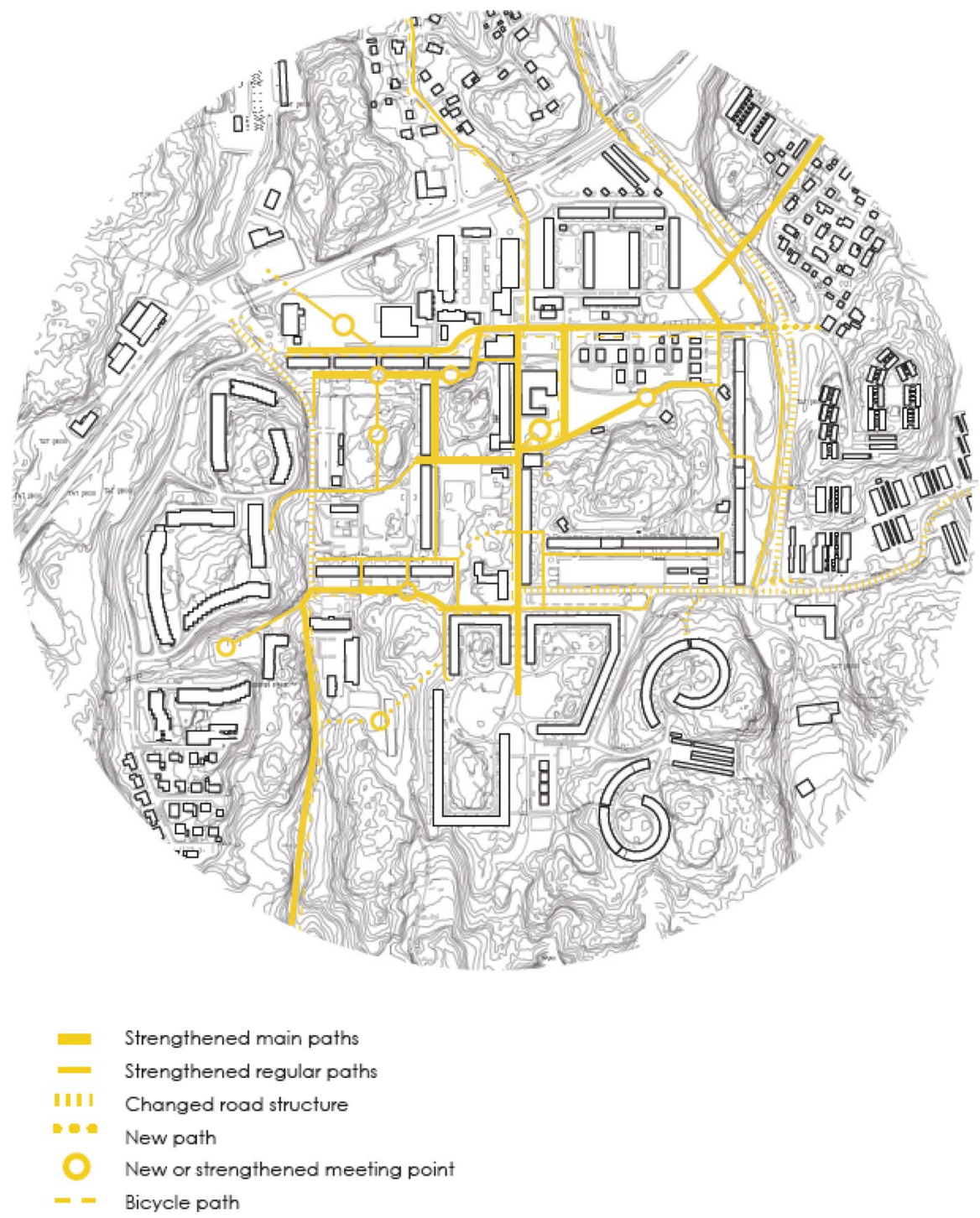

Fig. 6 Proposed changes for the orientation and movements layer of densification. Locations for changes of paths and roads. (Dvorak et al. 2015)

existing tram stop, the library, the civic office, and cultural and educational institutions. People feel unsafe in the square, especially at night, when criminals sell drugs there. During the winter months, the climate in the square, with its strong cold winds, is a major problem. There are few visual qualities, and maintenance is neglected. The proposal for the square focused on safety and vibrancy, aiming to attract more people. It redefined the square by adding new buildings and design elements that give people a reason to stay instead of just passing through. There is an 


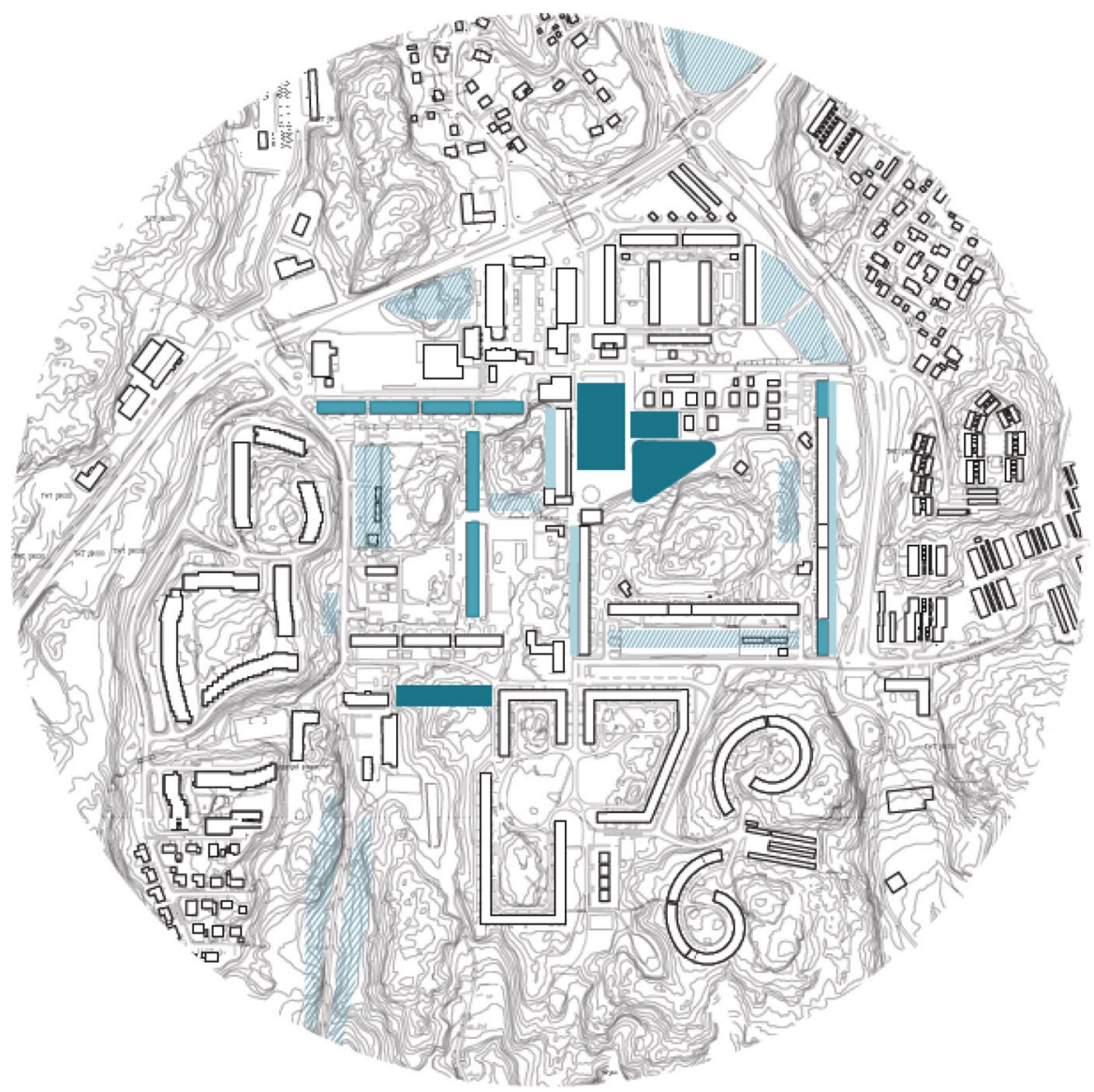

- New housing with facilities on first floor

- Facilities on first floor in existing building

Wh New building mainly housing

- Open up building (adding balconies, semi private spaces and entrances)

Fig. 7 Proposed changes for the built form layer of densification. Location for transformation of existing buildings and construction of new buildings. (Dvorak et al. 2015)

emphasis on semi-private space. The new buildings accommodate dwellings, student housing, offices, and ground floors for services.

The results of the work, including the design proposals, were presented to residents and representatives from the local planning office in feedback sessions. They were also publicly presented in Hammarkullen for residents, local staff of the housing company, and everyone interested. These meetings were organised in small groups of people, who were quite active in the discussions. A special presentation was made for the Chalmers University research group 'Compact Cities' for comments, feedback, and common learning. In order to improve outreach 


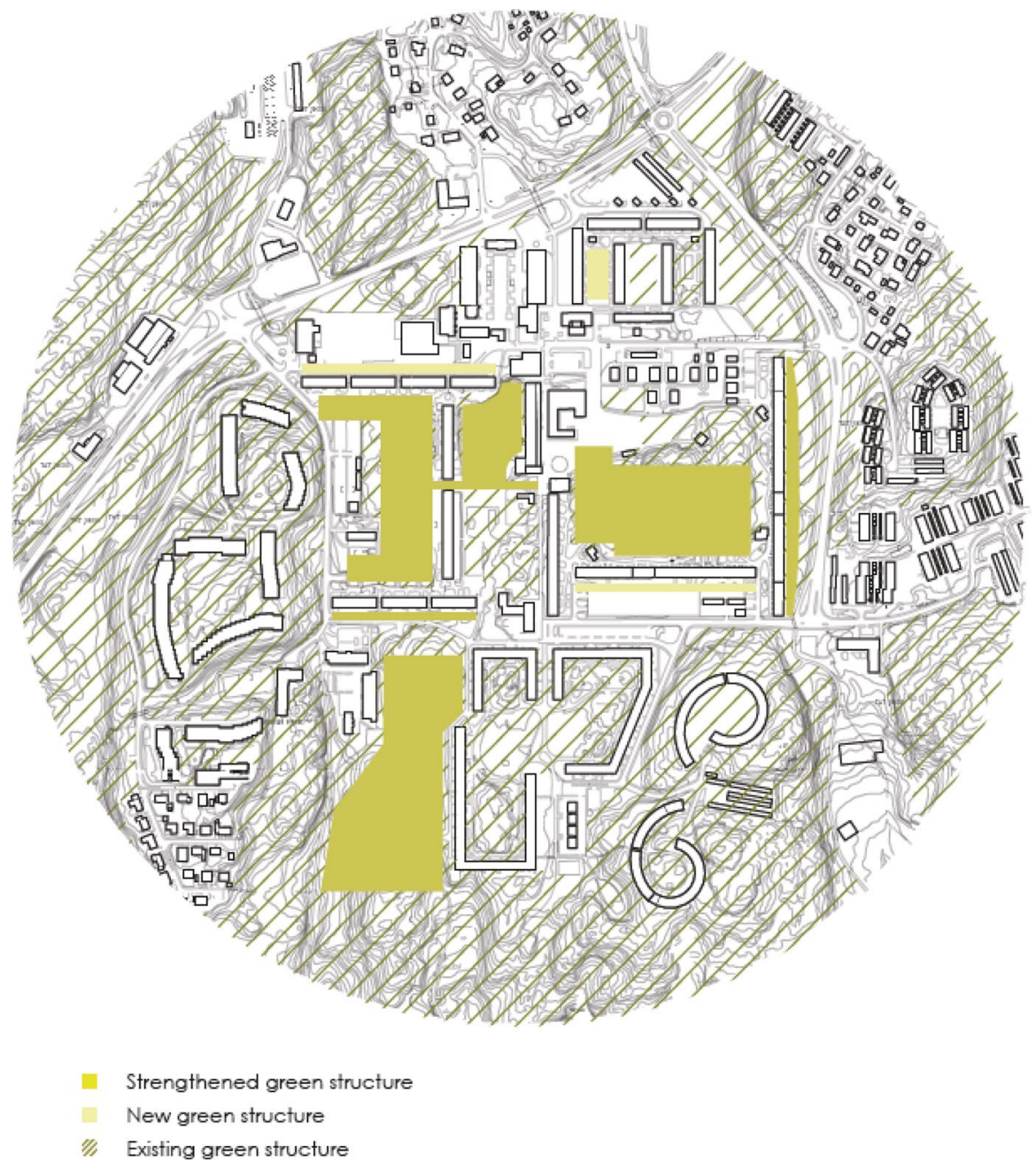

Fig. 8 Proposed changes for the green structure layer of densification. Locations for strengthening existing green structure and creation of new green structures. (Dvorak et al. 2015)

and obtain feedback from the municipality and the architectural and planning professions, critics from these categories were invited to the final critical session of the project, where the students received feedback from their potential future employers. At the same time, the participants in the session were given an opportunity to obtain up-to-date knowledge on how stigmatised neighbourhoods can be densified and developed based on residents' opinions and needs. 


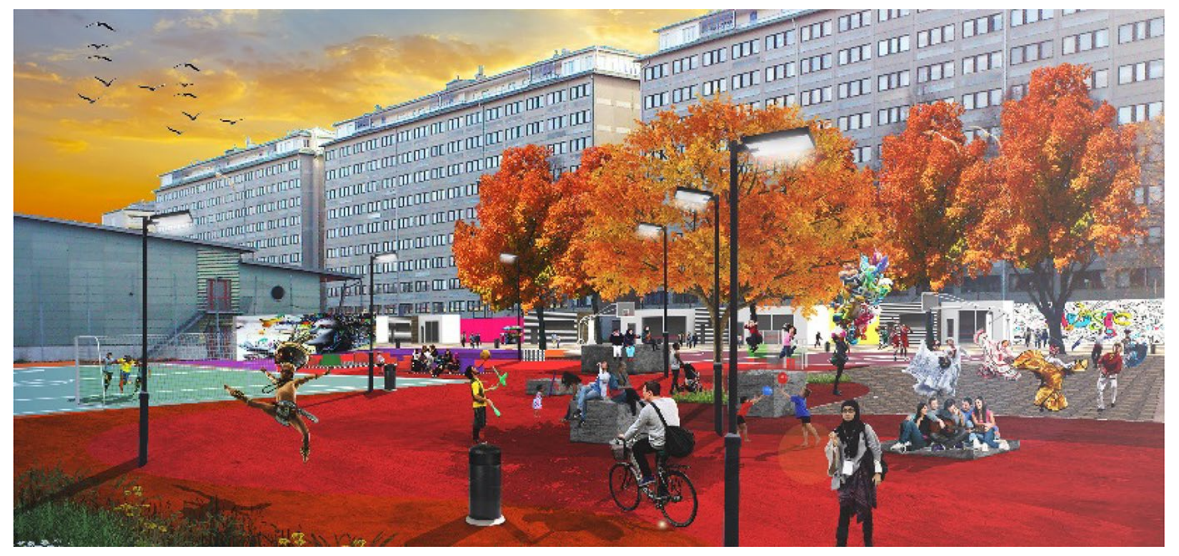

Fig. 9 Proposed leisure activity areas at Bredfällsgatan. (Dvorak et al. 2015)

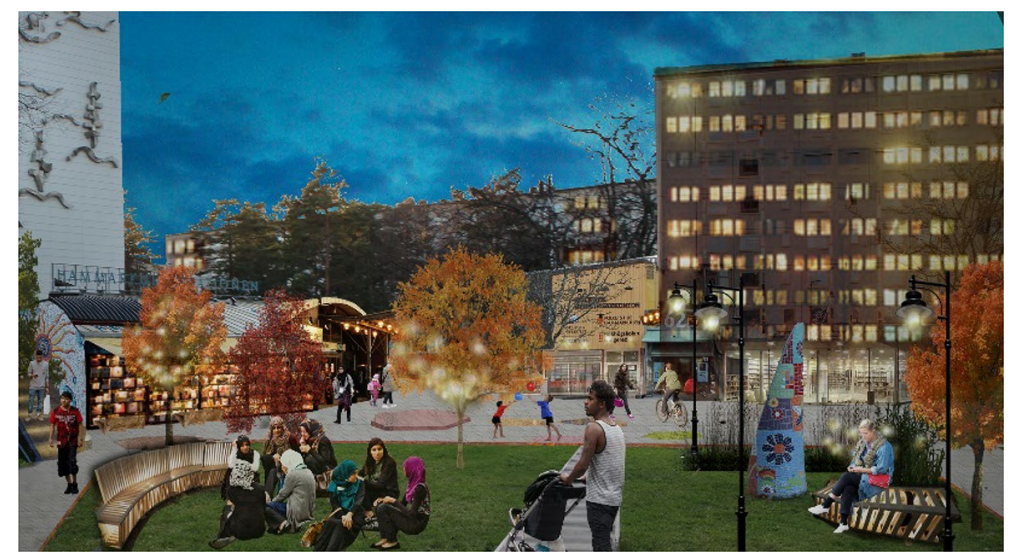

Fig. 10 Proposed new housing creates more social life. (Dvorak et al. 2015)

\section{Discussion and conclusions}

The present paper aims to examine three potential positive outcomes of linking education, research, and community outreach, namely that such linking may improve research activities, that it may have a positive impact on student learning, and that better valorisation of research results may be achieved.

\section{Quality of research}

The findings indicate that linking research, education, and community outreach may contribute significantly to research results. The engagement of students provided 
extra time resources for the study, enhancing the dialogue with residents and other local actors. Empirical data in the form of survey interviews were collected, and the pop-up workshop resulted in additional data, not least a mapping of locations in the neighbourhood with positive and negative connotations. This mapping of perceptions and the related identification of potential places for improvement in workshops with residents was conducted in the same format in the other two case cities of the Compact Cities research project, i.e., Rotterdam and Barcelona, facilitating crosslearning between the case cities. Students' involvement as action researchers also enabled additional knowledge input from and through the students. Such students represent the point of view of recently educated professionals with a 'young' mode of communicating and 'young' critical perspectives. It seems reasonable to argue that unique, or at least complementary, knowledge can be produced through studies based on codesign methods and by including residents, where students act as initiators and driving forces.

The students' assignment was to identify values and problems linked to the compact city concept when it is applied to an area such as Hammarkullen. Rather than starting from the physical environment, as architects, planners, and other designers tend to do, the residents guided the students towards a social perspective as the starting point for urban densification. Furthermore, the residents' involvement enabled a better understanding of what social aspects to focus on, as well as of the locations where these social problems could best be addressed through physical interventions. Still, the residents' involvement is not a guarantee of validity. As indicated in the quote at the beginning of "The neighbourhood of Hammarkullen" section, outsiders always run the risk of misunderstanding the local reality, even when engaging with residents. Nevertheless, based on the positive results from this case study, we can anticipate that other projects that use collaborative knowledge production can achieve better knowledge outcomes, which can lead to improved decision-making.

By combining these empirical results with the literature on compact cities, the students were able to develop design proposals for how the physical structure could be improved, as well as specific and detailed design proposals for how the two places that residents highlighted as the most problematic could be changed. For example, the students stated that any proposed buildings must contribute to social intensification outdoors because, according to the residents, one main problem was that too few people moved between the buildings. Instead of trying to solve social problems (e.g., drug dealing and intimidation in the square) using solely social measures (e.g., more local police officers), the residents emphasised that new built environments must be designed so that they increase the number of 'ordinary' people circulating outdoors. In addition to making the research more relevant, such findings are also important because they lead to the identification of more pertinent questions for future research.

\section{Student learning}

This studio has helped me in questioning my perceptions, but also in understanding how to communicate with different stakeholders and how much par- 
ticipation can mean for the residents, but also for the final result of a project. (Student 2)

By integrating research and higher education, students had access to researchers' knowledge and the latest research findings; by integrating learning and community outreach, students gained socially relevant knowledge. Moreover, through realitybased studies, they learned how to apply transdisciplinary methods in quite challenging situations, far from those depicted in textbooks. Here, the students noted that working with a topic that was still undefined because it was part of ongoing research was both challenging and educational. By conducting their own studies, they had to comprehend both how to define the topic and how to work. In this way, they learned a great deal about controlling the development of the project and how to evaluate it.

What the students developed in their master's project was the capacity to think about the compact city and its values in different terms and to critically assess what aspects should actually be densified. In this way, they showed how the design professions could be developed in a new direction. If the design professions, with their rather narrow focus on the built environment, are not repositioned, then they will not be able to properly handle 'wicked' problems (Batty 2014) or complex urban issues. The students identified the need for a systemic change in the design and planning praxis, as well: the need to make it socially relevant and thus able to face present and future urban challenges. This is indeed an impressive example of student learning.

So much depends on the individuals in charge, and this makes for a very fragile system. It is also remarkable that there is so little knowledge of what happens in other parts of the municipality. Many of the things that are occurring are also disconnected from the local context. If this is the case, how are the residents going to know who to contact and when? Not even one of the most dedicated residents had knowledge about this. It is not a matter of the officials in the municipality being bad at their jobs; it is a question of disorganisation, which is visible in many municipalities. ... One thing that is worth commenting on is also that many people we have met with have had a need to express themselves. This can be a result of lacking communication channels, which can be the outcome from lacking organisation. (Student 1)

\section{Valorisation of research results}

The students presented their findings and proposals to the residents and other stakeholders at the end of the studio project, and their work can be seen as completing one cycle of PAR (research/action/reflection) as discussed in "Introduction" section. Nevertheless, to enhance its empowering potential beyond the already remarkable value of a student project, such a research activity would need to have stronger action and reflection components and also undergo multiple cycles. Still, apart from the input for the larger research project on compact cities, the students' results are also highly relevant for the municipal planners and architects in Gothenburg who are currently faced with the task of densifying Hammarkullen. For that purpose, 
four municipal actors have come together to form a common strategy, and the public housing company that owns 2200 rented apartments in Hammarkullen is part of this strategy. The local management of this housing company has collaborated closely with the master's course since 2008.

This collaboration has influenced the assignments given to the students every year by linking them to ongoing development work, and often, members of the company act as extra supervisors when the students perform their work, e.g., by carefully guiding students when they approach the residents. However, the housing company staff have not had the power to influence how the students performed their work and, for obvious reasons related to hierarchies of power, they have not participated on a regular basis in the meetings between students and residents. In joint workshops, the students have applied their knowledge about power aspects and used different methods to equalise power differences. Overall, the housing company has always shown great interest in the students' work, and the local staff usually attend the outreach presentations. Some students have even been employed to further develop their design ideas after finishing their studies. This successful valorisation of research results at the local level has also taken place with locally based staff from the city district administration, such as employees at the youth centre, and with civil society organisations, such as the Swedish Union of Tenants.

In this local context, and in relation to the wider municipal context as described in the introduction, the students' elaborations of the novel concept of social intensification have (or could have) a significant value in relation to the city's ongoing densification ambitions in Hammarkullen. In Sweden, residents of vulnerable neighbourhoods often do not feel confidence in societal representatives (Stenberg and Fryk 2012; Listerborn 2007). Architects and planners are experts in the fields in which they are trained. However, many of those who work in municipalities today have not been trained in taking responsibility for social aspects, as well, and for integrating such aspects with aesthetic, technical, climatic, economic, and other issues. Their lack of competence in the social domain makes it difficult for them to meet and interact with residents who insist that they should handle the entirety of the densification challenge that is necessary for them to live a good life despite their vulnerable position and situation. Before the 1990s, when social problems were not as severe in Sweden and there were more resources for social work, architects and planners could rely on other actors to take on this social responsibility. Today, as resources are limited, and as major societal challenges require the integration of all aspects into all activities, urban professionals must take on a broader responsibility, and they need to be trained for this task.

However, the valorisation of the results from the students' work higher up in the hierarchies has not been as easy compared to their valorisation at the very local level. The master's course meets the abovementioned training need, but the students met resistance with practicing architects and planners. As is customary in architectural education at Chalmers, representatives of architecture and planning practice were invited to comment on the project at the end of the master's course. In the discussion about this project, a gap emerged between the invited architects and planners and the master's students. The fact that densification is needed due to a general housing shortage was not under debate; both parties 
agreed on that, but there was disagreement regarding the focus of such densification. The invited professionals focused on adding as much building volume as possible to increase the overall population density. In contrast, the master's students expressed the residents' desires, which were oriented towards maintenance and densification in ways aimed at promoting social values. The invited professionals did not acknowledge this novel understanding linking physical densification to processes of social intensification and remained within their more quantitative mind-set. Such a failure to acknowledge the value of local perceptions would mean a crucial difference for those who live in the area. What the master's students showed was that, when residents contribute knowledge about their own area's qualities and problems, and when architects and planners use this knowledge, societal resources invested in densification can contribute to enhancing the quality from the perspective of the residents, rather than-as is quite often the case in densification projects-lowering it.

There was thus a strong barrier to a valorisation of the transdisciplinary research results with a wider professional audience, which raises questions linked to the architect and planning communities' proficiency when it comes to seeing the value of citizen dialogue and fairness. There is sometimes a contradiction in policies that govern professional architects and planners and their actual actions. Policies embrace arguments for integrated (e.g., including both spatial and social aspects) and participatory approaches to architecture and planning, which can be described as the 'espoused theory' (Argyris and Schön 1996) when analysing actions from an organisational learning perspective. The praxis of architect planners to continue planning without integrating the residents' knowledge may be described as 'theory-in-use' (Argyris and Schön 1996). This mismatch between theory and praxis actually hinders practicing architect planners from engaging with critical issues of the renovation and regeneration of stigmatised neighbourhoods. In Hammarkullen, this discrepancy between the professional discourse and action is particularly important at present, as the four municipal partners now plan to make major investments in regeneration. If they are to take advantage of the benefits of codesign, professionals who are used to relying on their own creativity and expertise will have to embrace the idea that the experiential knowledge of residents is as valuable as their own expertise (Sanches and Frankel 2010).

Finally, a particular benefit of visible and engaging community-based research is the potential it has to open up the minds of young people with immigrant backgrounds towards university. It creates possibilities to pursue higher education for the aforementioned social categories and brings the universities closer to broader parts of our society. Sweden is experiencing severe and increasing problems of social exclusion of residents with a foreign background from higher education, and all universities have been given a directive by the government to widen their intake. Linking research, education, and community outreach has great potential to contribute to a positive development because this presence and collaboration with residents in research and education activities open the doors to mutual benefits. 


\section{Topics for future research}

Based on our experiences, there are some topics we believe merit further research. The present study indicates that research on the compact city needs to have a strong social focus in parallel with its focus on other aspects, such as spatial and functional issues. This is particularly interesting to investigate further in stigmatised largescale housing areas built in the 1960s and 1970s, because planners', developers', and residents' perspectives on what adequate densification actually entails seem to differ radically. Furthermore, the collaboration between the students and researchers was mutually beneficial, resulting in significant learning in both groups. However, given that education and research activities often have quite different rationales and time frames, there is a need for methodological development in both education and research to bridge these differences. This is particularly important when students are engaged in reality-based studies of open systems, i.e., not desk studies, to avoid leaving students in the position of being too unsupervised and vulnerable. Finally, the apparent mismatch between what planners and urban professionals say and what they do is not a new observation (Schön 1995), but it nonetheless emphasises the need for a better understanding of how the planning system can coproduce urban knowledge and action with other stakeholders, including citizens. This will become even more critical since the rapid development of new ICT tools for crowd-sourced knowledge and action requires public officials to develop daily routines that make them both proactive and resilient in relation to the impact of such technologies.

Acknowledgements We would like to thank the master's students Jakub Dvorak, Siri Ersson, Luisa Sarvia, Caroline Sollerhed, and Jonathan Westlin, as well as Emilio Brandão, examiner of the master's course at Chalmers Architecture. The research project 'Compact Cities? Exploring qualities, drivers, and strategies for promoting mixed-use urban development' was funded between 2014 and 2017 by the Swedish Research Council Formas (Reg. No. 250-2013-1295).

Funding Open access funding was provided by Chalmers University of Technology.

Data availability All data generated or analysed during this study are included in this published article and its supplementary information files.

\section{Declarations}

Conflict of interest On behalf of all authors, the corresponding author states that there is no conflict of interest.

Open Access This article is licensed under a Creative Commons Attribution 4.0 International License, which permits use, sharing, adaptation, distribution and reproduction in any medium or format, as long as you give appropriate credit to the original author(s) and the source, provide a link to the Creative Commons licence, and indicate if changes were made. The images or other third party material in this article are included in the article's Creative Commons licence, unless indicated otherwise in a credit line to the material. If material is not included in the article's Creative Commons licence and your intended use is not permitted by statutory regulation or exceeds the permitted use, you will need to obtain permission directly from the copyright holder. To view a copy of this licence, visit http://creativecommons.org/licen ses/by/4.0/. 


\section{References}

Al-Kodmany K (2001) Bridging the gap between technical and local knowledge: tools for promoting community-based planning and design. J Arch Plan Res 18(2):110-130

Andersson R (2002) Boendesegregation och etniska hierarkier (Housing Segregation and Ethnic Hierarchies). In: Lindberg I, Dahlstedt M (eds) Det slutna folkhemmet: Om etniska klyftor och blågul självbild (The Introvert Swedish Welfare State). Agora, Stockholm, pp 115-151

Andersson R, Bråmå Å, Hogdal J (2009) Fattiga och rika—segregationen ökar Flyttningsmönster och boendesegregation i Göteborg 1990-2006. Göteborgs Stad, Göteborg

Argyris C, Schön DA (1996) Organizational learning II: theory, method, and practice. Addison-Wesley, Reading

Argyris C, Putnam C, Smith McLain D (1985) Action science: concepts, methods, and skills for research and intervention. Jossey-Bass Inc., Publishers, San Francisco

Batty M (2014) Great planning disasters. In: Tewdwr-Jones M et al (eds) The planning imagination: P. Hall and the study of urban and regional planning. Routledge, London and New York, pp 28-39

City of Gothenburg (2014) Development strategy Gothenburg 2035. The Planning and Building Authority, Gothenburg. Available at https://goteborg.se/wps/wcm/connect/9c52d58d-af74-4494-89e0759d852a528e/ENG_UP_kap1-4.pdf?MOD=AJPERES

City of Gothenburg (2016a) Göteborgsbladet—områdesfakta (Area Data), Göteborg_SDN, SCB/Stadsledningskontoret, Göteborgs Stad. Available at http://statistik.goteborg.se/Global/Faktablad/G\% c3\%b6teborgsblad/GbgBlad2016/G\%c3\%b6teborg_SDN.pdf

City of Gothenburg (2016b) Göteborgsbladet—områdesfakta (Area Data), Angered_PRI, SCB/Stadsledningskontoret, Göteborgs Stad. Available at http://statistik.goteborg.se/Global/Faktablad/G\%C3\% B6teborgsblad/GbgBlad2016/G\%C3\%B6teborgsblad\%202016-\%20Folkh\%C3\%A41soomr\%C3\% A5den.pdf

Derr V (2015) Integrating community engagement and children's voices into design and planning education. CoDesign 11(2):119-133

Dewalt K, Dewalt B (2010) Participant observation. US AltaMira Press, Lanham

Dvorak J et al (2015) Social Intensification: a project on how to work with densification in Hammarkullen. Unpublished students report. Chalmers University of Technology, Gothenburg

Echenique MH et al (2012) Growing Cities sustainably. J Am Plann Assoc 78(2):121-137

Faga B (2006) Designing public consensus: the civic theater of community participation for architects, landscape architects, planners, and urban designers. Wiley, Hoboken

Groat L, Wang D (2002) Architectural research methods. Wiley, Chich

Hirsch Hadorn G, Hoffmann-Riem H et al (2008) Handbook of transdisciplinary research. Springer, Berlin

Hirt S, Luescher A (2007) Collaboration between architects and planners in an urban design studio: potential for interdisciplinary learning. J Design Res 6(4):422-443

Howard AL (2010) Engaging the City: civic participation and teaching urban history. J Urban Hist 36(1):42-55

Kindon S, Pain R, Kesby M (eds) (2007) Participatory action research approaches and methods: connecting people, participation and place. Routledge, New York

Listerborn C (2007) Who speaks? And who listens? The relationship between planners and women's participation in local planning in a multi-cultural urban environment. GeoJournal 70:61-74

McNall MA et al (2015) Systemic engagement: Universities as partners in systemic approaches to community change. J High Educ Outreach Engagem 19(1):1-25

Neuman M (2005) The Compact City fallacy. J Plan Educ Res 25(1):11-26

Novy A (2012) "Unequal diversity" as a knowledge alliance: an encounter of Paulo Freire's dialogical approach and transdisciplinarity. Multicult Educ Technol J 6:137-148

Oteros-Rozas EB et al (2015) Participatory scenario planning in place-based social-ecological research: insights and experiences from 23 case studies. Ecol Soc 20(4):32

Ranger A, Westerberg K (2004) Metoder för möten (methods for meetings). Miljöförvaltningen, Malmö Stad

Reason P, Bradbury H (2001) Handbook of action research. Sage, London

Rogge ME, Rocha CJ (2014) University-Community Partnership Centers. J Community Pract 12(3-4):103-121 
Roussou E et al (2019) Social inclusion: when community outreach becomes the core of architectural education. Facts and figures about a studio in the Master programme Architecture and planning beyond sustainability 2014-2018. Report. Chalmers University of Technology, Gothenburg

Sanches M, Frankel L (2010) Co-design in public spaces: an interdisciplinary approach to street furniture development. Design research society conference. University of Montreal, Montreal

Sanders EBN et al (2008) Co-creation and the new landscapes of design. CoDesign Int J CoCreation Design Arts 4(1):5-18

Sandmann LR et al (2016) Building the field of higher education engagement: a 20-year retrospective. J High Educ Outreach Engagem 20(2):1-14

Schoffelen J et al (2015) Visualising things. Perspectives on how to make things public through visualisation. CoDesign Int J CoCreation Design Arts 11:179-192

Schön DA (1995) The reflective practitioner: how professionals think in action, 4th edn. Basic Books Inc., Aldershot

Stenberg J, Fryk L (2012) Urban empowerment through community outreach in teaching and design. Procedia Soc Behav Sci 46:3284-3289. https://doi.org/10.1016/j.sbspro.2012.06.052

Steyaert S, Hervé L (eds) (2005) Participatory methods toolkit: a practitioner's manual. King Baudouin Foundation and the Flemish Institute for Science and Technology Assessment (viWTA), Belgium

Trencher G et al (2016) The role of students in the co-creation of transformational knowledge and sustainability experiments: experiences from Sweden, Japan and the USA. In: Leal Filho W, Brandli L (eds) Engaging stakeholders in education for sustainable development at University Level. Springer, Berlin, pp 191-215

\section{Authors and Affiliations}

\section{Jenny Stenberg ${ }^{1} \cdot$ Liane Thuvander $^{2}\left(\mathbb{D} \cdot\right.$ Jaan-Henrik Kain ${ }^{1} \oplus \cdot$ Marco Adelfio $^{3}$}

1 Gothenburg Research Institute, University of Gothenburg, Viktoriagatan 13, 41125 Gothenburg, Sweden

2 Division of Architectural Theory and Method, Department of Architecture and Civil Engineering, Chalmers University of Technology, Sven Hultins Gata 6, 41296 Gothenburg, Sweden

3 Division of Urban Design and Planning, Department of Architecture and Civil Engineering, Chalmers University of Technology, Sven Hultins Gata 6, 41296 Gothenburg, Sweden 